\title{
APONTAMENTOS SOBRE OS NEGÓCIOS JURÍDICOS PROCESSUAIS NO NCPC 2015
}

Olivie Samuel Paião, Murilo Teixeira Rainho

Universidade do Oeste Paulista - UNOESTE, Curso de Direito, Presidente Prudente, SP. E-mail: olivie2007@hotmail.com

\section{RESUMO}

Este trabalho traz apontamentos sobre os negócios jurídicos processuais, bem como a relevância jurídica que ganharam com a inserção e vigência no Novo Código de Processo Civil de 2015. Abordou-se a conceituação dos negócios jurídicos processuais, em síntese, que se trata da possibilidade das partes convencionarem o que melhor as prouver no tocante às matérias de ordem processuais. Corrobora, também, tal negociação para os deslindes processuais de forma célere, buscando uma solução consensual de conflitos sem a intervenção total do judiciário, evitando-se, inclusive, a formação de um processo de conhecimento. Assim, após a introdução, abordar-se-á o instituto de forma mais aprofundada, na parte da discussão, apontando a nova roupagem no processo civil, qual seja, diminuir as demandas no judiciário. Por fim, conclui-se o trabalho demonstrando as inovações trazidas pelo NCPC no tocante ao negócio jurídico processual, bem como a importância do presente artigo.

Palavras-Chave: Código Processual Civil. Direito Material. Negócio Jurídico Ato Jurídico. Acordo de partes.

\section{APPOINTMENTES ON PROCEDURAL LEGAL BUSINESSES IN NCPC 2015}

\begin{abstract}
This paper provides notes on the legal and procedural business, as well as the legal relevance they gained with the insertion and validity in the New Code of Civil Procedure of 2015. It was discussed the conceptualization of the juridical proceedings, in summary, that is the possibility of the parties to agree on what best suits them as regards procedural matters. It also corroborates such negotiation for procedural delimitations expeditiously, seeking a consensual solution of conflicts without the total intervention of the judiciary, avoiding, even, the formation of a process of knowledge. Thus, after the introduction, the institute will be addressed in more depth, in the part of the discussion, pointing out the new clothing in the civil process, that is, to reduce the demands in the judiciary. Finally, the paper concludes the work demonstrating the innovations brought by the NCPC regarding the procedural legal business, as well as the importance of this article.
\end{abstract}

Keywords: Code of Civil Procedure. Material Law. Business Legal Law. Parties Agreement. 


\section{INTRODUÇÃO}

O presente trabalho buscou demonstrar de maneira sintetizada as inovações trazidas pelo atual Código de Processo Civil no tocante aos negócios jurídicos processuais, o qual possibilita as partes negociarem sobre normas processuais dentro do processo.

O código trouxe, ainda, os meios alternativos de solução de conflitos, tipos de negócios que visam a acabar com a cultura da busca pelo judiciário para a resolução de contendas.

Diante da relevância do tema para a matéria processual e dos impactos práticos que essa mudança de paradigma vem trazendo ao ordenamento jurídico, justificou-se a elaboração do presente trabalho.

Os negócios jurídicos processuais foram aperfeiçoados e ampliados com a vigência do $\mathrm{CPC} / 15$, entretanto não nasceram com o código, pois os antigos regramentos já traziam previsão acerca do tema, inclusive o código de 1973, todavia as hipóteses de negociação eram limitadas. O grande exemplo que sempre esteve presente na doutrina, é a chamada cláusula de eleição de foro dos contratos, trata-se de um negócio jurídico processual que modifica as regras de competência do processo diante da arguição da vontade das partes.

Assim, o objetivo da presente pesquisa, é de demonstrar, de maneira sintetizada, as inovações trazidas pelo CPC, no tocante ao negócio jurídico processual, bem como interar o corpo acadêmico da viabilidade e intuito do novo código de processo civil.

\section{METODOLOGIA}

O artigo respaldou-se em pesquisas bibliográficas, das quais resultaram a leitura e análise de leis, resoluções e artigos eletrônicos. As informações foram analisadas e confrontadas com uso da dialética. A metodologia científica utilizada foi o método dedutivo, isto é, partindo de uma análise de princípios gerais para o particular.

\section{DISCUSSÃO}

Antes de adentrarmos diretamente a discussão do presente artigo, necessita-se esclarecer o que vem a ser o negócio jurídico. Trata-se, pois, da manifestação da vontade humana buscando criar, modificar, conservar ou extinguir relações jurídicas- o grande fundamento desse instituto é a declaração da vontade humana que regulará as consequências do negócio.

Assim, os atos jurídicos, em sentido amplo, quando decorrentes da vontade humana, cujos efeitos tem repercussão no mundo jurídico, bem como existe previsão legal, estamos diante dos negócios jurídicos. Nesse sentido:

Assim, negócio jurídico (Rechtsgeschaft) é o acordo de vontades, que surge da participação humana e projeta efeitos desejados e criados por ela, tendo por fim a aquisição, modificação, transferência ou extinção de direitos. Há, nesse passo, uma composição de interesses (é o exemplo típico dos contratos), tendo a declaração de vontades um fim negocial.

[...] negócio jurídico é o "ato de autonomia privada, com o qual o particular regula por si os próprios interesses. Por outras palavras, é o ato regulamentador dos interesses privados".

É, pois, mais rico e complexo, em sua estrutura interna, do que o ato jurídico (no qual a vontade é apenas para aderir aos efeitos previstos na ordem jurídica), seja pelo seu conteúdo, seja pela produção de efeitos. No negócio, há uma composição de interesses, um regramento de condutas estabelecido bilateralmente, entre as partes envolvidas no acontecimento. Essa exteriorização de vontade presente no negócio jurídico tem o escopo negocial, visando criar, adquirir, transferir, modificar ou extinguir direitos. (FARIAS; ROSENVALD, 2015, p. 500/501). 
Nesse diapasão, sob a ótica do negócio jurídico, sabendo-se que não se visa a dissecar o conceito em si, Azevedo (2002, p. 16) descreve que:

Todo fato jurídico consistente na declaração de vontade, a que o ordenamento jurídico atribui os efeitos designados como queridos, respeitados os pressupostos de existência, validade e eficácia impostos pela norma jurídica que sobre ele incide.

Para Orlando Gomes (1995, p. 269), trata-se de "toda declaração de vontade destinada à produção de efeitos jurídicos correspondentes ao intento prático do declarante se reconhecido e garantido pela lei".

De acordo com Flávio Tartuce, aos negócios jurídicos é atribuído o seguinte conceito:

Esse instituto pode ser conceituado como sendo toda a ação humana, de autonomia privadas, com a qual os particulares regulam por si os próprios interesses, havendo uma composição de vontades, cujo conteúdo deve ser lícito. Constitui um ato destinado à produção de efeitos jurídicos desejados pelos envolvidos e tutelados pela norma jurídica.

[...] O negócio jurídico típico é o contrato, concebido como um negócio jurídico bilateral ou plurilateral que visa à criação, à modificação ou à extinção de direitos e deveres, com conteúdo patrimonial - conceito clássico ou moderno retirado do artigo 1321 do Código Civil Italiano de 1942. É imperioso repetir que todo contrato constitui negócio jurídico, sem exceção; o que justifica a importância da teoria geral do negócio jurídico para a seara contratual. Dessa forma o negócio jurídico é o principal instrumento que as pessoas têm para realizar seus interesses, sendo relevante salientar a importância da Parte Geral do Código Civil para a própria concepção de contrato. (2015, p. 347).

Apenas a saber, dividem-se os referidos negócios jurídicos em planos, quais sejam, existência, validade e eficácia- o primeiro é uma criação doutrinária, não sendo tratado pelo código civil atual, o qual é necessário para a existência do referido negócio os seguintes elementos cumulativos: i) agente; ii) objeto; iii) forma e iv) vontade humana exteriorizada/ consentimento.

Pois bem, conforme já dito, o negócio jurídico é um tema em que o código civil sempre voltou seus olhos e deu destaque, contudo, na esfera processual o referido instituto tornou-se objeto do atual Código de Processo Civil, que possibilitou as partes acordarem sobre regras processuais, quando de comum acordo.

Os negócios jurídicos podem ser bilaterais ou unilaterais derivados de acordos ou convenções (espécies de negócios jurídicos), essas são as características dos atos.

Toda norma processual é cogente, inderrogável e de ordem pública, sua fonte decorre de lei escrita, salvo convenção das partes, esse pensamento predominou durante toda a vigência do código de 1973, decorria do publicismo processual que defendia a inadmissibilidade do processo convencional, ou seja, as partes não podiam por acordo de vontade convencionarem sobre o procedimento, salvo se partissem para a arbitragem.

Durante muitos anos o tema não era abordado, ficando esquecido pela doutrina, contudo com o atual código o instituto passou a ser novamente objeto de estudo, na verdade, hoje em dia, existe um movimento mundial de estudo dos negócios jurídicos processuais, principalmente nos países que adotam o sistema common law, diante da liberdade das partes em convencionarem normas processuais.

Os negócios jurídicos processuais já existiam nos códigos antigos, não é uma novidade do $\mathrm{CPC} / 15$, entretanto ao instituto nunca foi dado o devido valor, a inovação trazida pelo código é voltada a fortalecer esse instituto.

Nota-se que o atual código processual apenas inovou o instituto, mas não o criou na esfera processual, a prova disso é que a arbitragem é um negócio jurídico processual que já existe há 20 anos. 
O artigo 200 do CPC/15 repetiu o texto legal do artigo 158 do CPC/73, entretanto inovou, quando possibilitou a criação de negócios jurídicos processuais anteriores a lide, na formação dos contratos e durante a lide, bem como de forma atípica, na negociação de normas e procedimentos processuais, conforme será analisado a seguir (BRASIL, 2015).

Art. 200. Os atos das partes consistentes em declarações unilaterais ou bilaterais de vontade produzem imediatamente a constituição, modificação ou extinção de direitos processuais.

Parágrafo único. A desistência da ação só produzirá efeitos após homologação judicial.

É importante extrair desse tópico que os negócios jurídicos processuais não surgiram com o $\mathrm{CPC} / 15$, já existiam nos outros códigos, entretanto ao instituto não era dado valor, diante do pensamento existente derivado do publicismo processual, que pregava que as partes só poderiam convencionar de forma livre fora do processo judicial, através da arbitragem, com o surgimento do novo código foi atribuída liberdade as partes para convencionarem sobre normas processuais nos litígios.

Os negócios jurídicos processuais no CPC/15 tem previsão no artigo 190, chamado de cláusula geral, disposição que possibilita as partes transacionarem sobre os atos processuais presentes no processo, mudanças no procedimento e diversas outras questões.

Art. 190. Versando o processo sobre direitos que admitam autocomposição, é lícito às partes plenamente capazes estipular mudanças no procedimento para ajustá-lo às especificidades da causa e convencionar sobre os seus ônus, poderes, faculdades e deveres processuais, antes ou durante o processo.

Parágrafo único. De ofício ou a requerimento, o juiz controlará a validade das convenções previstas neste artigo, recusando-lhes aplicação somente nos casos de nulidade ou de inserção abusiva em contrato de adesão ou em que alguma parte se encontre em manifesta situação de vulnerabilidade (BRASIL, 2015).

Podem, inclusive, serem praticados na fase pré processual, durante a formação dos contratos, ou na fase processual (do litígio), desde que o processo verse sobre direitos que permitam a composição (os chamados direitos disponíveis), podendo intervir no procedimento, convencionar sobre os ônus, os poderes, faculdades e deveres.

O CPC inova na amplitude desses atos. O novo código foi criado buscando a mudança de paradigma da legislação brasileira, o pensamento vigente sempre foi da solução de conflitos através da lide, da intervenção do judiciário para pacificação dos conflitos, o novo código veio em contramão, buscando fomentar a composição célere e amigável, motivo pelo qual deu ampla liberdade às partes para convencionarem dentro dos processos- ou fora deles.

Duas grandes mudanças merecem destaque. A primeira consiste no disposto no artigo $327 \S 2$ 2 do CPC, permitindo a incorporação de módulos de procedimentos especiais no bojo do procedimento comum. Já a segunda mudança consiste no artigo 190 do CPC, a cláusula geral dos negócios processuais, marcada por uma saliente distinção, porquanto ingressa pela porta da democratização processual, abre as partes algo semelhante a uma técnica de montagem de procedimentos especiais. Autoriza o estabelecimento de negócios jurídicos processuais atípicos, vinculativos para as partes e para o julgador, que surtem efeitos independentemente de homologação judicial, ou seja, as partes são dotadas para promover adaptações no procedimento, de forma a normatizar parcela do exercício da jurisdição (DI SPIRITO, 2015).

Entretanto, as disposições não podem significar uma forma de burlar a legislação vigente, posto que ao mesmo tempo que o legislador ampliou a atuação das partes no processo, determinou a fiscalização pelo judiciário sobre os atos praticados, a fim de evitar nulidades e abusos nos procedimentos.

O CPC adotou o princípio do respeito ao autorregramento da vontade no processo, um 
modelo cooperativo de processo, com valorização da vontade das partes e equilíbrio nas funções dos sujeitos processuais. Nesse sentido, o juiz não pode valer-se de fundamento a respeito do qual não se tenha oportunizado manifestação das partes (artigo 10 do CPC). A preocupação aqui é pela criação de um espaço não apenas para julgamento de uma demanda, mas para a verdadeira solução de conflitos.

O velho judiciário, caracterizado pelo distanciamento do julgador e pelo formalismo típico das audiências, aonde as partes apenas assistem a realização dos atos, intervindo apenas quando questionadas é substituído por um modelo pautado no debate, no diálogo e pela intervenção do conciliador ou mediador. Ocorrendo o fortalecimento do princípio da autonomia da vontade (CABRAL, 2016).

Nota-se que o CPC traz a ideia do gerenciamento dos processos pelo magistrado, existindo para as partes uma flexibilização do procedimento, permitindo a chamada negociação processual, tratando-se então de um negócio jurídico processual.

Esses podem ser firmados dentro do processo ou em fases antecedentes, como já dito. No mais, o CPC também deixou em evidência os meios alternativos de solução de conflitos. Nesse sentido:

Poder-se-ia então dimensionar acordos das partes no processo, com eficácia substancial, como as conciliações judiciais e os acordos tácitos de não contestação; os acordos no processo, com atos praticados fora do mesmo com eficácia interna, inclusive sobre os poderes judiciais, como a convenção de arbitragem e os acordos sobre provas; e os acordos no processo para o processo, que corresponderiam aos contratos processuais, previstos, por exemplo, no art. 764 do Nouveau Code Francês ou em nosso CPC 2015. (THEODORO JUNIOR, 2016, p. 260).

Na mesma linha de raciocício, acrescenta Almeida (2014, p. 104) que "o acordo processual não visa solucionar o conflito, mas regulamentar, nos moldes desejados pelas partes, o próprio método de solução, isto é, o exercício da jurisdição. Consiste em convenção pactuada fora do processo, mas com eficácia endoprocessual".

Ademais, entende-se que, a possibilidade da criação de negócios jurídicos processuais viabiliza o estabelecimento de uma cláusula de acordo de procedimentos no processo, onde as partes da lide, juntamente com o juiz, poderiam, a título de exemplo, estabelecer um calendário para-processual, dentre os outros acordos.

Contudo, conforme dispõe oa autor Humberto Theodoro Junior, tais acordos se dão com mais frequência na esfera ou fase extrajudicial, isto é, em momento pré-processual. Veja-se:

No entanto, é inegável que o maior âmbito de aplicação da cláusula de negociação processual dar-se-á na fase pré-processual. Neste momento, poderão ser realizados ajustes antes da eclosão do litígio.

[...] De toda sorte, a proposta que agora vem sendo debatida oferece uma perspectiva mais ambiciosa: "preconiza-se, modernamente, a possibilidade de partes e juiz, em clima de cooperação, ajustarem acordo de natureza exclusivamente processual a respeito da condução do processo e de momento da prática de determinados atos processuais. (2016, p. 262).

Independentemente do momento de utilização do negócio jurídico processual, o que importa é a efetivação de um judiciário mais célere e econômico, alcançando as metas de solução rápida e pacífica de conflitos, sob a fiscalização do magistrado, colocando a atuação desse último como subsidiária, isto é, fazendo com que as partes, por acordo de vontades, cheguem a um consenso e uma solução. 


\section{CONCLUSÃO}

O presente trabalho fez breves apontamentos acerca dos negócios jurídicos processuais, instituto que ganhou força com o Código de Processo Civil de 2015, possibilitando as partes acordarem sobre normas processuais, em fase pré processual ou dentro do processo. $O$ estudo do tema é de extrema relevância ante o impacto causado no ordenamento jurídico, ainda mais com a vigência do novo código que trouxe uma nova roupagem e aplicabilidade deste instituto.

O atual código processual busca acelerar a resolução das demandas e trazer resultados efetivos ao processo ao fomentar a composição das lides. A realidade em nosso ordenamento são demandas judiciais morosas e resultados ineficazes para ambas as partes, o que não é vantajoso para o judiciário, Estado e particular.

Dessa forma, os negócios processuais buscam a mudança do paradigma de que só as demandas judiciais são capazes de resolver os conflitos. O código busca fortalecer os meios alternativos de solução de conflitos extra processuais, ou seja, negócios jurídicos firmados entre as partes, através de composição, mediação ou arbitragem, sem a necessidade de um enfrentamento judicial, colaborando com os princípios da economia e celeridade processuais, bem como reduzindo a quantidade de processos que abarrotam o judiciário.

\section{REFERÊNCIAS}

AZEVEDO, Antonio Junqueira de. Negócio jurídico: existência, validade e eficácia. 4 edição. Editora Saraiva. São Paulo, 2002.

ALMEIDA, Diogo Assumpção Rezende de. Das convenções processuais no processo civil. Tese de Doutorado em Direito. Rio de Janeiro: Faculdade de Direito da Universidade do Estado do Rio de Janeiro, 2014.

BRASIL. Lei no. 13.105/2015. Código de Processo Civil. Disponível em:< http://www.planalto.gov.br/ccivil_03/_ato2015-2018/2015/lei/l13105.htm>. Acesso em 17 ago. 2018.

CABRAL, Antônio do Passo. CRAMER, Ronaldo. Comentários ao novo código de processo civil. 2ª edição, revista atualizada e ampliada. Editora Forense, 2016.

DI SPIRITO, Marco Paulo Denucci. Controle de formação do negócio jurídico processual - Parte II. Artigo cientifico publicado na revista de processo. Ano 40, vol. 248, outubro/2015. Coordenação Teresa Arruda Alvim Wambier. Instituto Brasileiro de Direito Processual - IBDP. Thomson Reuters, Revista dos Tribunais, São Paulo, 2015.

FARIAS, Cristiano Chaves de. ROSENVELD, Nelson. Curso de direito civil 1. Parte geral e LINDB. 13a edição, revista ampliada e atualizada. Editora Atlas S.A. 2015.

TARTUCE, Flávio. Direito civil 1. Lei de Introdução e Parte Geral. 11a Edição, Editora Método, São Paulo, 2015.

THEODORO JUNIOR, Humberto. NUNES, Dierle. BAHIA, Alexandre Melo Franco. PEDRON, Flávio Quinaud. Novo CPC. Fundamentos e Sistematização. Lei 13.105, de 16.03.2015. 2a edição, editora Forense, Rio de Janeiro, 2016. 
THEODORO JUNIOR, Humberto. Novo código de processo civil anotado. 20ạ Edição. Editora forense. Rio de Janeiro- RJ, 2016. 